NASA/CR-1999-209304
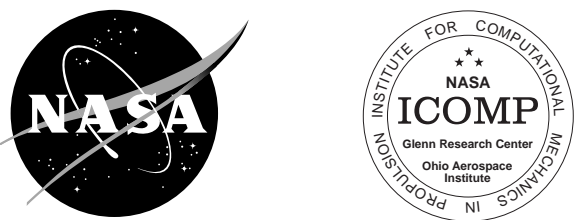

\title{
Simulation of Unsteady Hypersonic Combustion Around Projectiles in an Expansion Tube
}

S. Yungster and K. Radhakrishnan

Institute for Computational Mechanics in Propulsion, Cleveland, Ohio 
Since its founding, NASA has been dedicated to the advancement of aeronautics and space science. The NASA Scientific and Technical Information (STI) Program Office plays a key part in helping NASA maintain this important role.

The NASA STI Program Office is operated by Langley Research Center, the Lead Center for NASA's scientific and technical information. The NASA STI Program Office provides access to the NASA STI Database, the largest collection of aeronautical and space science STI in the world. The Program Office is also NASA's institutional mechanism for disseminating the results of its research and development activities. These results are published by NASA in the NASA STI Report Series, which includes the following report types:

- TECHNICAL PUBLICATION. Reports of completed research or a major significant phase of research that present the results of NASA programs and include extensive data or theoretical analysis. Includes compilations of significant scientific and technical data and information deemed to be of continuing reference value. NASA's counterpart of peerreviewed formal professional papers but has less stringent limitations on manuscript length and extent of graphic presentations.

- TECHNICAL MEMORANDUM. Scientific and technical findings that are preliminary or of specialized interest, e.g., quick release reports, working papers, and bibliographies that contain minimal annotation. Does not contain extensive analysis.

- CONTRACTOR REPORT. Scientific and technical findings by NASA-sponsored contractors and grantees.
- CONFERENCE PUBLICATION. Collected papers from scientific and technical conferences, symposia, seminars, or other meetings sponsored or cosponsored by NASA.

- SPECIAL PUBLICATION. Scientific, technical, or historical information from NASA programs, projects, and missions, often concerned with subjects having substantial public interest.

- TECHNICAL TRANSLATION. Englishlanguage translations of foreign scientific and technical material pertinent to NASA's mission.

Specialized services that complement the STI Program Office's diverse offerings include creating custom thesauri, building customized data bases, organizing and publishing research results ... even providing videos.

For more information about the NASA STI Program Office, see the following:

- Access the NASA STI Program Home Page at http://www.sti.nasa.gov

- E-mail your question via the Internet to help@sti.nasa.gov

- Fax your question to the NASA Access Help Desk at (301) 621-0134

- Telephone the NASA Access Help Desk at (301) 621-0390

- Write to:

NASA Access Help Desk

NASA Center for AeroSpace Information 7121 Standard Drive

Hanover, MD 21076 
NASA/CR-1999-209304

AIAA 99-2640
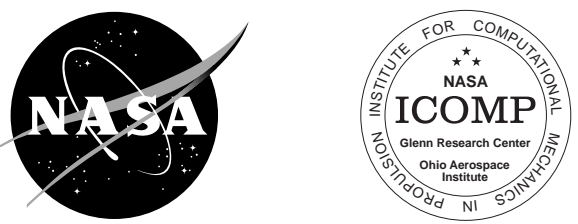

\section{Simulation of Unsteady Hypersonic Combustion Around Projectiles in an Expansion Tube}

S. Yungster and K. Radhakrishnan

Institute for Computational Mechanics in Propulsion, Cleveland, Ohio

Prepared for the

35th Joint Propulsion Conference and Exhibit cosponsored by AIAA, ASME, SAE, and ASEE

Los Angeles, California, June 20-24, 1999

Prepared under Cooperative Agreement NCC3-542

National Aeronautics and

Space Administration

Glenn Research Center 
Available from

NASA Center for Aerospace Information 7121 Standard Drive

Hanover, MD 21076

Price Code: A03
National Technical Information Service 5285 Port Royal Road Springfield, VA 22100 Price Code: A03 


\title{
SIMULATION OF UNSTEADY HYPERSONIC COMBUSTION AROUND PROECTILES IN AN EXPANSION TUBE
}

\author{
S. Yungster ${ }^{*}$ and K. Radhakrishnan ${ }^{\dagger}$ \\ Institute for Computational Mechanics in Propulsion \\ National Aeronautics and Space Administration \\ Glenn Research Center \\ Cleveland, Ohio 44135
}

\begin{abstract}
The temporal evolution of combustion flowfields established by the interaction between wedge-shaped bodies and explosive hydrogen-oxygen-nitrogen mixtures accelerated to hypersonic speeds in an expansion tube is investigated. The analysis is carried out using a fully implicit, time-accurate, computational fluid dynamics code that we developed recently for solving the Navier-Stokes equations for a chemically reacting gas mixture. The numerical results are compared with experimental data from the Stanford University expansion tube for two different gas mixtures at Mach numbers of 4.2 and 5.2. The experimental work showed that flow unstart occurred for the Mach 4.2 cases. These results are reproduced by our numerical simulations and, more significantly, the causes for unstart are explained. For the Mach 5.2 mixtures, the experiments and numerical simulations both produced stable combustion. However, the computations indicate that in one case the experimental data were obtained during the transient phase of the flow; that is, before steady state had been attained.
\end{abstract}

\section{Introduction}

The development of new detonation-wave-based propulsion devices, such as the ram accelerator [1], oblique detonation wave engine [2] and pulse detonation engine [3], has renewed interest in studying the combustion of premixed gases flowing at hypersonic speeds. Recently, a new experimental technique-based on the expansion tube-was developed by Srulijes et al. [4] and Morris et al. [5,6] to investigate such flows. In the expansion tube, combustible gas mixtures are accelerated to hypersonic speeds and then allowed to interact with stationary test bodies. The resulting flowfield can produce various modes of shock-induced combustion, ranging from decoupled shock-deflagration waves to overdriven detonation waves.

The expansion tube consists essentially of a single tube divided into three or four sections by diaphragms, as shown in Fig. 1, which is a schematic of the classic expansion tube developed by Trimpi [7]. When the test gas comprises an explosive mixture, a buffer zone (not shown in Fig. 1) con-

\footnotetext{
*Senior Member AIAA.

$\dagger$ Senior Member AIAA.
}

taining an inert gas is added between the test gas and the driver gas, to prevent autoignition following rupture of the primary diaphragm [4].

The principal advantage of the expansion tube over the shock tube and shock tunnel in applications involving premixed combustible gases is that the operating cycle does not involve stagnation of the test gas. Therefore, explosive mixtures can be accelerated to hypersonic velocities without autoignition.

Other methods have also been used to study shock-induced combustion flowfields. For example, Lehr [8] used ballistic range experiments, in which projectiles were fired at high speeds into premixed hydrogen-air mixtures. However, one disadvantage of this technique is that measurements are difficult to make on a moving projectile. In contrast, in the expansion tube the test models are stationary, thereby simplifying data collection.

The main difficulties associated with the expansion tube (and pulse facilities in general) are the short test times available (up to half a millisecond) and the relatively low total pressures attainable. A rule of thumb when air is the test gas is that, to assure flow establishment, the pulse facility must supply a "slug" of air that is three times longer than the test model $[9,10]$. For chemically reacting flows, especially if recirculation zones and shock wave/boundary layer or detonation wave/boundary layer interactions are present, the slug of test gas may have to be longer than the recommended value, as shown in this paper. Thus, because of the finite test time available, it may not be possible to determine experimentally the required flow establishment time for a given reactive mixture and operating condition.

Computational fluid dynamics (CFD) simulations can help resolve the above issue, because they do not have test time limitations. Thus important questions, such as the existence of a steady state and the test time required for its establishment, can be answered by CFD. Also, CFD can be used to extrapolate test results to the high pressures where propulsion systems will actually operate and which cannot currently be attained in the laboratory. Thus CFD can serve as a powerful method for complementing experimental work. 
In this paper we present results of our numerical simulations of five experiments conducted in the Stanford University expansion tube by Morris et al [5,6] and make qualitative comparisons with their observations. Recently, Choi et al. [11] also carried out numerical simulations of two of the problems examined in this work. Although we do not show their results, we make comparative observations. The main objective of our study is to investigate the details of combustion initiation and temporal evolution of the flowfield, in order to better understand the flow physics and explain the experimental observations. In addition, these experiments serve as new benchmark test problems for our ongoing program on developing and validating an accurate, efficient and robust CFD code for studying high speed, chemically reacting, viscous flows [12-16].

\section{Expansion Tube Cycle}

A brief explanation of the operation of the expansion tube is given below, in order to put into perspective the time domain of our calculations. Figure 1 shows a schematic diagram of the expansion tube cycle. Following rupture of the primary diaphragm at time $t=t_{0}$, a primary shock wave $\left(s_{1}\right.$ in Fig. 1) propagates into the test gas, and an expansion wave into the driver gas. On reaching the end of the driven section, the primary shock ruptures the secondary diaphragm and a secondary shock wave $\left(s_{2}\right)$ propagates downstream into the expansion section, while an expansion wave moves upstream into the test gas. This expansion wave is washed downstream, since the gas in region 2 is moving at supersonic speeds. Test time begins with the arrival of the test gas/accelerating gas contact discontinuity $\left(c_{2}\right)$ at the model, and ends with the arrival of the expansion wave. The state of the gas in region 5 determines the test condition.

Our interest in the present work is to examine the flow and combustion processes resulting from the interaction of the high speed combustible mixture with the test model. Therefore, our simulations are performed for time $t \geq t_{2}$ (see Fig. 1).

\section{Numerical Formulation}

\section{Governing Equations}

The conservation form of the unsteady Navier-Stokes and species transport equations describing two-dimensional or axisymmetric, chemically reacting flows can be written in general curvilinear coordinates $(\xi, \eta)$ as follows:

$$
\frac{\partial \boldsymbol{Q}}{\partial t}+\frac{\partial\left(\boldsymbol{F}-\boldsymbol{F}_{v}\right)}{\partial \xi}+\frac{\partial\left(\boldsymbol{G}-\boldsymbol{G}_{v}\right)}{\partial \eta}+j\left(\boldsymbol{S}-\boldsymbol{S}_{v}\right)=\boldsymbol{W}
$$

where $t$ is time, the parameter $j$ is zero for two-dimensional flow and one for axisymmetric flow and $\boldsymbol{Q}$ is the vector of dependent variables for a gas mixture containing $N$ species:

$$
\boldsymbol{Q}=J^{-1}\left[\rho_{1}, \rho_{2}, \ldots, \rho_{N}, \rho u, \rho v, e\right]^{T}
$$

The dependent variables are the mass density of the $i$ th species $\rho_{i}(i=1, \ldots, N)$, the velocity components $u$ and $v$ and the total energy per unit volume $e . J$ is the grid Jacobian and $\boldsymbol{F}$ and $\boldsymbol{G}$ are the inviscid flux vectors in the $\xi$ and $\eta$ directions, respectively. $\boldsymbol{F}_{v}$ and $\boldsymbol{G}_{v}$ are analogous viscous fluxes. $\boldsymbol{S}$ and $\boldsymbol{S}_{v}$ are axisymmetric source terms and $\boldsymbol{W}$ is the chemical source term. A detailed description of the terms in equation (1) and additional state and constitutive equations needed for system closure are given by Yungster [17].

All five cases examined in this study involve mixtures of hydrogen, oxygen and nitrogen. The chemical reaction mechanism was taken from Jachimowski [18], except reactions involving nitrogen are not considered, because they become important only at higher Mach numbers than considered here. The resulting combustion mechanism consists of 19 elementary reactions among 8 reacting species and the inert species $\mathrm{N}_{2}$ [12].

\section{$\underline{\text { Numerical Method }}$}

The numerical method used for solving equation (1) is described by Yungster and Radhakrishnan [12] and summarized below. For clarity in presentation, only the two-dimensional Euler equations are considered here-extension to the viscous case is, however, straightforward [12]. The equation set is discretized using the backward differentiation formula (BDF) method [19], because its accuracy and efficiency in solving the ordinary differential equations arising in combustion chemistry have been well established [20,21].

Define the time step $\Delta t^{n}=t^{n+1}-t^{n}$, the time step ratio $r_{t}=\Delta t^{n} / \Delta t^{n-1}$ and the change in the vector of dependent variables $\Delta \boldsymbol{Q}^{n}=\boldsymbol{Q}^{n+1}-\boldsymbol{Q}^{n}$. Then the second-order, variable-step BDF method applied to equation (1) gives for the time interval $\left[t_{n}, t_{n+1}\right]$

$$
\begin{array}{r}
\Delta \boldsymbol{Q}_{j, k}^{n}=\gamma \Delta \boldsymbol{Q}_{j, k}^{n-1}-\beta \Delta t^{n}\left[\tilde{\boldsymbol{F}}_{j+1 / 2, k}-\tilde{\boldsymbol{F}}_{j-1 / 2, k}+\right. \\
\left.\tilde{\boldsymbol{G}}_{j, k+1 / 2}-\tilde{\boldsymbol{G}}_{j, k-1 / 2}-\boldsymbol{W}_{j, k}\right]^{n+1}
\end{array}
$$

where the BDF method coefficients $\gamma$ and $\beta$ are

$$
\gamma=\frac{r_{t}^{2}}{1+2 r_{t}}, \quad \beta=\frac{1+r_{t}}{1+2 r_{t}}
$$

The terms $\tilde{\boldsymbol{F}}$ and $\tilde{\boldsymbol{G}}$ are the numerical fluxes in the $\xi$ and $\eta$ directions. They are computed using Yee's second order total variation diminishing (TVD) scheme [22]. Equation (3) is then linearized in a conservative manner and solved iteratively, by using a lower-upper relaxation procedure consist- 
ing of successive Gauss-Seidel (LU-SGS) sweeps. At each time step the iterative process of producing successively improved approximate solutions to equation (3) is continued until a suitable convergence criterion is satisfied $[12,19]$.

The inversion of large matrices is avoided by partitioning the system into reacting and nonreacting parts. Consequently, the matrices that have to be inverted are of the same size $(N \times N)$ as those that arise in the commonly used point implicit methods. A fully coupled interaction between the flow and chemistry is, however, maintained through the subiteration process. An important advantage of the present method is that, because it is fully implicit, it is stable for large values of the CFL number, thereby enabling the use of relatively large time steps to minimize computational cost.

\section{Results}

In this section we present results of our numerical simulations of reaction initiation and development in the Stanford University expansion tube $[5,6]$ for five different cases. We also compare our results with available experimental $\mathrm{OH}$ planar laser induced fluorescence (PLIF) data and, although not shown here, with the numerical solutions of Choi et al [11], who recently conducted a CFD study of the expansion tube flowfield. The test condition and reactive gas mixture composition are given in Table 1 for all five cases. In this table $p, T$ and $M$ refer to the pressure, temperature, and Mach number, respectively. The subscripts 5, 10 and 20 denote the expansion tube regions shown in Fig. 1 and the subscript CJ refers to the Chapman-Jouguet condition corresponding to the gas mixture at state $5 ; M_{\mathrm{CJ}}$ was computed with the NASA chemical equilibrium code CEA [23]. Note that all five cases involve flow at superdetonative speeds; that is, the test gas velocity is greater than the CJ detonation speed.

Although helium was used as the accelerating gas in the experiments, hydrogen was selected in the numerical simulations for computational simplicity. This change in the accelerating gas does not significantly affect the results in the time interval of interest, because the two gases have similar specific heat ratios and the accelerating gas is not involved in the combustion process. This simplifying assumption was also made by Choi et al [11].

Figures 2a-c show the experimental OH PLIF images for cases 1-3. Cases 4 and 5 resulted in flow unstart, and no $\mathrm{OH}$ PLIF image was given by Morris et al. [5,6].

\section{$\underline{\text { Case } 1}$}

The first case studied the flow at Mach 5.2 (i.e., $M_{5}=5.2$ ) of a $2 \mathrm{H}_{2}+\mathrm{O}_{2}+17 \mathrm{~N}_{2}$ mixture over a $40^{\circ}$ wedge-shaped projectile of length $L=30 \mathrm{~mm}$, as shown in Fig. 3a. For this test problem we assumed turbulent flow and adiabatic projectile wall. Zero-order extrapolation was used for the top and right boundaries. The Baldwin-Lomax turbulence model [24] was utilized, and a $313 \times 85$ grid was found to adequately resolve the flow features.

Figures 3a-h show the temporal evolution of the reacting flowfield, by means of water mass fraction contours (top half of each figure) and normalized temperature $\left(T / T_{10}\right)$ contours (bottom half of each figure). These figures show the reflection of the expansion tube's secondary shock $\left(s_{2}\right.$; see Fig. 1) by the wedge (Fig. 3a), followed by arrival of the contact discontinuity $\left(c_{2}\right.$; see Fig. 1) and high-speed combustible gas mixture (Fig. 3b). As the combustible mixture reaches the projectile, an oblique shock wave begins to form (Fig. 3c). Subsequently, at $t \approx 29 \mu \mathrm{s}$, combustion is initiated along the boundary layer (Fig. 3d). Combustion is initially limited to the boundary layer, but it then begins to expand laterally at a location just upstream of the projectile shoulder (Figs. 3e-h). At $t \approx 92 \mu$ s the solution becomes essentially time independent (Fig. 3h); that is, steady state is obtained.

The lateral expansion of the combustion front (Figs. 3e-h) can be explained as follows. Combustion in the boundary layer causes the oblique shock wave to curve slightly, thereby increasing its strength. Consequently, the induction time decreases along the length of the wedge and combustion intensifies near the projectile shoulder. However, the shock wave-combustion front interaction is weak, and so a decoupled shock-deflagration wave system is obtained.

The computed steady state solution is also shown in Fig. 4, but in the form of $\mathrm{OH}$ mass fraction contours. Comparing this figure to the corresponding experimental $\mathrm{OH}$ PLIF image (Fig. 2a) shows the good qualitative agreement between the computed structure of the combustion zone and the experimental result. At $t=92 \mu \mathrm{s}$, the approximate flow establishment time for case 1, the test "slug" of combustible gas mixture is $166 \mathrm{~mm}$ long, or about 5.5 times wedge length-significantly longer than the suggested value $(\sim 3 \times L)$ for nonreacting test gases $[9,10]$.

\section{$\underline{\text { Cases 2-5 }}$}

Cases 2-5 consider hypersonic flow over two $20^{\circ}$ wedges arranged symmetrically, as shown in Fig. 5a. This configuration is similar to the hollow projectiles used by Thibault $e t$ al. [25] and Sasoh et al. [26] in their ram accelerator studies. The test flow domain is $61 \mathrm{~mm}$ long, with a constant cross-sectional area region $12.7 \mathrm{~mm}$ high. After Choi et al. [11], who carried out numerical simulations of cases 2 and 3 $\left(M_{5}=5.2\right.$; see Table 1), we assume adiabatic walls, laminar flow and zero-order extrapolation for the outflow boundary, in order to facilitate comparison with their results. For these two cases also, the flow features were resolved adequately with a $313 \times 85$ grid. 
The first stage of flow development, that is, from arrival of the secondary shock until combustion initiation, is very similar for cases 2-5. Therefore, we show this period of flow development (which covers approximately the first 75-80 $\mu$ s) only for case 2 , which involves the flow of a $2 \mathrm{H}_{2}+\mathrm{O}_{2}+$ $17 \mathrm{~N}_{2}$ mixture at Mach 5.2 (see Table 1). The results are given in Figs. 5a-1, in the form of normalized temperature $\left(T / T_{10}\right)$ contour lines. In Fig. 5 and subsequent figures (6-9), the contour range, given in the form (minimum, maximum, increment), applies for the plot in which the range is specified and for every subsequent plot, until a new range is defined.

Time is measured from the instant when the secondary shock $\left(s_{2}\right)$ is $3 \mathrm{~mm}$ upstream of the leading edge of the test model (Fig. 5a). As the secondary shock moves over the test model, it is reflected and a complex system of oblique shocks and expansion waves is established (Figs. 5b-f). After approximately $32 \mu \mathrm{s}$, the oblique shocks coalesce into a normal shock that moves slowly upstream (Figs. $5 \mathrm{~g}$ and $5 \mathrm{~h}$ ). At approximately $40 \mu \mathrm{s}$, just before the normal shock wave moves out of the computational domain (Fig. 5h), the contact discontinuity $\left(c_{2}\right)$ (followed by the high-speed test gas) overtakes the normal shock (Fig. 5i). (It should be pointed out that in the Stanford University experiments $[5,6]$ the reacting mixture arrives at the projectile at a later time than we have assumed. We chose an earlier time, in order to avoid having to use an unnecessarily long computational domain. This simplifying assumption should not significantly affect the subsequent reacting flow. The same approach was adopted by Choi et al [11].)

The interaction between the contact discontinuity and the normal shock produces a new normal shock (Fig. 5i) that travels downstream, and can be seen leaving the computational domain at $t \approx 56 \mu$ s (Fig. $5 \mathrm{j}$ ). As the high speed test gas mixture begins to flow over the model, a shock wave system begins to form that is attached to the two wedges (Fig. $5 \mathrm{j}$ ). This system consists of a pair of weak and strong oblique shocks interconnected by a normal shock. At approximately $70 \mu \mathrm{s}$ the two strong oblique waves collide and the normal shock disappears (Fig. 5k). Later, at $t \approx 76 \mu \mathrm{s}$, this interaction results in the formation of a new normal shock between the two weak oblique shocks waves at the leading edges (Fig. 51). At this time the first stage of flow development (i.e., the preignition regime following secondary shock arrival at the projectile) is essentially over, because combustion initiation occurs soon, as discussed next.

The temperature behind the normal shock is high enough to cause ignition of the mixture. Combustion begins at $t \approx 85$ $\mu \mathrm{s}$, as shown in Fig. 6a, which gives normalized pressure $\left(p / p_{10}\right)$ contour lines overlaid on $\mathrm{OH}$ mass fraction contours. Production of $\mathrm{OH}$ is observed in Fig. 6a to occur downstream of the normal shock, separated by a short induction zone. Subsequently, the flame front moves closer to the nor- mal shock (Figs 6b and 6c), and concurrently the width of the normal shock decreases: eventually, the oblique-normal shock system transitions into a regular oblique shock reflection (Fig. 6d). The temperature behind the reflected oblique wave is, however, not high enough to maintain combustion, and so the flame detaches from the oblique shock (Figs. 6e and 6f). The flame is then washed downstream, out of the computational domain (Figs. 6g-i). (Transient combustion phenomena in expansion tubes is not surprising, inasmuch as it was observed in our previous studies of unsteady reacting flowfields in these devices [13].)

Combustion in the boundary layer is observed to begin at $t \approx 103 \mu \mathrm{s}$, mainly around the region where the oblique shock impinges on the body surface (Fig. 6d). The shock wave-boundary layer interaction creates a separated flow region, which acts as a flameholder (Figs. 6d-i). When steady state is attained at $t \approx 197 \mu \mathrm{s}$, combustion persists only inside the boundary layer upstream of the projectile shoulder, within the separated flow region and along the reattached boundary layer downstream (Fig. 6i). This time corresponds to an effective mixture slug $319 \mathrm{~mm}$ long, or 5.2 times model length-again much longer than the recommended value for air $[9,10]$.

The structure of the computed steady state flowfield (Fig. 6i) shows good qualitative agreement with the experimental OH PLIF image (Fig. 2b). Note in particular that the experimental and numerical results both show that combustion is restricted to the separated flow region and boundary layer downstream-reaction is not observed in the central flow region. (It should be pointed out that the area imaged by the PLIF system did not extend to the model shoulder (see Ref. 6 and Fig. 2b). Hence some of the reacting region in Fig. 6i is not visible in Fig. 2b.)

We also compared our results with those reported recently by Choi et al [11] (results not shown here). Excellent agreement between the two solutions was obtained, both at steady state (compare Fig. 2c in [11] and Fig. 6i) and during flow establishment (i.e., the transient phase; see Fig 6 in [11] and Figs. 6a-i).

Case 3 also involves flow at Mach 5.2, but a different mixture $\left(2 \mathrm{H}_{2}+\mathrm{O}_{2}+12 \mathrm{~N}_{2}\right)$ than in case 2 (see Table 1). The temporal evolution of the computed postignition flowfield is shown in Figs. 7a-i, as superimposed $\mathrm{OH}$ mass fraction contours and normalized pressure $\left(p / p_{10}\right)$ contour lines. The flow development during this stage is similar to that of case 2: an initial period of combustion in the core region, followed by flame blow out, and then establishment of a stable reaction region in the separated flow region and in the boundary layer upstream and downstream of this region. But in case 3 combustion in the core flow region persists for a longer time period than in case 2 (compare Figs. 6h and 7f, which were both generated at approximately the same time 
point), due to the higher energy content of test gas mixture 3 (because of the smaller $\mathrm{N}_{2}$ concentration in mixture 3 than in mixture 2; see Table 1).

The flame remains attached to the oblique shock until approximately $132 \mu \mathrm{s}$ (Fig. 7f). Then detachment of the flame occurs and the combustion zone moves downstream-eventually out of the computational domain (Figs. 7g-i). The steady state flowfield (Fig. 7i), attained after approximately $194 \mu \mathrm{s}$, is similar to that for the previous case (see Fig. 6i), but the separated flow region is somewhat larger. The effective gas mixture slug length required for reacting flow establishment (i.e., the length corresponding to $t=194 \mu \mathrm{s})$ is $318 \mathrm{~mm}$, or again approximately 5.2 times model length.

Comparing the calculated steady state flowfield structure for case 3 (Fig. 7i) with the corresponding experimental $\mathrm{OH}$ PLIF image (Fig. 2c) shows that the experimental result indicates combustion along the center of the flow domain, whereas the numerical solution does not. However, the computed solution at earlier times, before steady state establishment, does display core flow reaction, as described above (see Figs. 7b-7h). Moreover, careful examination of Figs. $7 \mathrm{e}-\mathrm{g}$ shows that the experimental image given in Fig. 2c corresponds to the numerical solution obtained at some time between $\sim 120 \mu$ s and $\sim 140 \mu$ s (but not at steady state, Fig. $7 \mathrm{i})$. In order to ascertain the reason for the discrepancy at steady state between the computed and experimental flowfields, we compared our results with those of Choi et al [11]. As in case 2, excellent agreement was noted between the two computed flowfields, both at steady state (not shown here; see Fig. 2d in [11]) and during flow development (see Fig. 5 in [11]). Also, Choi et al. [11] remark on the absence of combustion in the central region of the computed flowfield, in contrast to the experimental result. It can therefore be concluded that the experimental image shown in Fig. 2c was obtained during the transient phase; that is, before steady state had been attained. In other words, the test time was not long enough for the reacting flow to become fully established

Cases 4 and 5 consider the same test model and gas mixtures as cases 2 and 3, respectively, but the test gas Mach number is 4.2 (see Table 1). For both cases 4 and 5, Morris et al. [6] reported flow unstart, sometimes followed by a detonation wave traveling up the expansion tube. No OH PLIF image was given for either case, and the cause of flow unstart could not be determined conclusively.

The postignition results of our numerical simulations for cases 4 and 5 are given in Figs. 8 and 9, respectively, as overlaid $\mathrm{OH}$ mass fraction contours and normalized pressure $\left(p / p_{10}\right)$ contour lines. Our initial calculations indicated that the $313 \times 85$ grid used for cases 1-3 was not fine enough to capture accurately the unstart process. To estimate the required axial grid spacing, we calculated the length of the induction zone behind a Mach 4.2 normal shock wave, by using the NASA kinetics code LSENS [21,27]. The induction zone lengths were $1.1 \mathrm{~mm}$ for case 4 and $0.8 \mathrm{~mm}$ for case 5 , respectively. A new $508 \times 180$ grid was created, with a variable grid spacing of $0.18 \mathrm{~mm}$ at the leading edge and $0.05 \mathrm{~mm}$ at the shoulder. Therefore, the induction zone would be resolved with a minimum of four grid points. In order to attain the higher grid resolution, the test model length was reduced to $42 \mathrm{~mm}$.

Figures 8a-j show the reacting flow development for case 4 and $t>75 \mu \mathrm{s}$. As in case 2 , the intersection of oblique shocks results in the formation of a normal shock (see Figs. $6 \mathrm{a}$ and 8a). However, note that the normal shock is now located farther upstream than in case 2 . Combustion in the core region is observed to exist from $t \approx 75 \mu$ s to $t \approx 127.5$ $\mu \mathrm{s}$, when the flame detaches from the reflected oblique shock and is washed downstream, leaving the computational domain (Figs. 8a-c). At $t \approx 160 \mu$ s, there is no longer any combustion in the central flow region (Fig. 8d).

Boundary layer combustion begins at approximately $100 \mu \mathrm{s}$ (Fig. 8b), and is clearly observed at $127.5 \mu$ s (Fig. $8 \mathrm{c}$ ). A separated flow region with intense combustion is formed, and the separated flow produces new weak oblique shocks (Fig. 8d). This region continues to grow, and propagates upstream of the projectile shoulder, generating additional weak oblique shocks (Figs. 8e-j). At $t \approx 190 \mu \mathrm{s}$, the multiple oblique shocks produced by the separated (and reacting) flow increase the temperature in the core region to above the autoignition temperature, thereby giving rise to a new combustion front in this region (Fig. 8f).

An oblique detonation wave forms, which propagates upstream of the projectile shoulder (Figs. 8g-h), thus increasing the pressure in that region and accelerating upstream flame propagation in the boundary layer. At $t \approx 219 \mu \mathrm{s}$, boundary layer combustion reaches the projectile leading edge (Fig. 8h). At this time, the boundary layer combustion cannot propagate further upstream; instead, it begins to propagate laterally towards the center of the flow channel (Fig. 8i). Subsequently, the laterally propagating flame interacts with the upstream-moving oblique detonation wave, forming a normal detonation wave, which is apparent at $t \approx 262 \mu \mathrm{s}$ (Fig. 8j). Note that in this case (and the next), because of detonation, the peak pressures are much higher than in cases 2 and 3 (see Figs. 6-9).

At this time, the calculation was stopped, because we had captured the essential features of the experimental observations-flow unstart and formation of a normal detonation wave that propagates upstream of the test model.

Figs. 9a-j illustrate the results of our numerical simulation of case 5 , which involves a more energetic mixture than, but the same test gas pressure and temperature as, case 4 . Figs. 8a-j and 9a-j show that the reacting flowfield develop- 
ment is very similar for the two cases, but in case 5 combustion in the core region is more intense than in case 4 and this flame does not leave the computational domain, However, as in case 4 , the oblique shocks generated by the separated flow reintensify combustion in the central region (Fig. 9f). Note that at this time $(t \approx 196 \mu \mathrm{s})$ combustion in the boundary layer has not propagated as far upstream as in case 4 (compare Figs. 8f and 9f).

Again, as in case 4, an oblique detonation wave is formed that propagates upstream of the projectile shoulder (Figs. $9 \mathrm{~g}-\mathrm{h}$ ), with an attendant rise in pressure, and flow unstart ensues. Also observed is the upstream propagation of the boundary layer flame, which reaches the leading edge of the projectile (see Figs. 9h and 9i), and then expands laterally into the core region (Fig. 9i). In this case, the oblique detonation wave propagating upstream splits into three distinct cells (Figs. 9h and 9i). The interaction between the oblique detonation wave system and the laterally expanding reacting boundary layer transforms this complex wave system into a normal detonation wave (Fig. 9j), as in case 4 (see Fig. 8j).

\section{Conclusions}

Numerical simulations of combustion flowfields resulting from the interaction of reactive mixtures accelerated to hypersonic speeds with projectiles in an expansion tube facility were performed, and results presented for five different cases. In all cases our computations reproduced qualitatively the experimental observations.

In the first case, which involved hypersonic flow around a $40^{\circ}$ wedge, stable shock-induced combustion, wherein the flame front was decoupled from the oblique shock, was obtained. The computed steady state combustion structure was in very good agreement with the experimental OH PLIF image. Combustion was shown to originate in the boundary layer. A slug of test gas mixture 5.5 times projectile length was required to attain steady state; that is, for reacting flow establishment. This length is about $80 \%$ longer than the recommended value for air. Thus additional research is required to determine flow establishment time for reacting flows in pulse facilities.

For the symmetrical $20^{\circ}$ wedge configuration and test gas Mach number of 5.2 (cases 2 and 3), the numerical solution reached steady state at approximately $190 \mu \mathrm{s}$. This time correspond to a test gas length of 5.2 times projectile length, again significantly longer than the recommended length for air.

In cases 2 and 3 , the computed steady state showed combustion only in the boundary layer, especially within the separated flow region created by the shock wave/boundary layer interaction. We found that our results agreed well with the numerical solutions of Choi et al [11]. For case 2, the experi- ments showed the same combustion structure as the calculations. However, for case 3, the experiments showed combustion along the central region of the flow, while the numerical results did not. This difference was attributed to the experimental data being recorded during the transient phase of the reacting flow; that is, before steady state had been established.

For the second configuration and test gas Mach number of 4.2 (cases 4 and 5), the simulations predicted flow unstart and the generation of a detonation wave, in agreement with the experimental observations. The flow unstart was shown to be caused by the boundary layer combustion propagating upstream of the projectile shoulder and towards its leading edge. This flame propagation produces a series of oblique shock waves that reignite the core flow, creating an oblique detonation wave whose interaction with the laterally expanding boundary layer flame gives rise to a normal detonation wave that propagates upstream.

\section{References}

1. Hertzberg, A., Bruckner, A.P. and Bogdanoff, D.W., "Ram Accelerator: A New Chemical Method for Accelerating Projectiles to Ultrahigh Velocities," AIAA Journal, Vol. 26, 1988, pp. 195-203.

2. Ostrander, M.J., Hyde, J.C., Young, M.F., Kissinger, R.D. and Pratt, D.T., "Standing Oblique Detonation Wave Engine Performance,” AIAA Paper 87-2002, June 1987.

3. Eidelman, S., Grossmann, W. and Lottati, I,. "Computational Analysis of Pulsed Detonation Wave Engines and Applications," AIAA Paper 90-0460, 1990.

4. Srulijes J., Smeets G. and Seiler F., "Expansion Tube Experiments for the Investigation of Ram Accelerator Related Combustion and Gasdynamic Problems," AIAA Paper 92-3246, January 1992.

5. Morris, C.I., Kamel, M.R., Stouklov, I.G., and Hanson, R.K., "PLIF Imaging of Supersonic Reactive Flows Around Projectiles in an Expansion Tube," AIAA Paper 96-0855, January 1996.

6. Morris, C.I., Kamel, M.R. and Hanson, R.K., "Expansion Tube Investigation of Ram Accelerator Projectile Flowfields," AIAA Paper 96-2680, July 1996.

7. Trimpi R.L., "A Preliminary Theoretical Study of the Expansion Tube, a New Device For Producing High-Enthalpy Short Duration Hypersonic Gas Flows," NASA Technical Report R-133, 1962.

8. Lehr, H.F., "Experiments on Shock-Induced Combustion," Acta Astronautica, Vol. 17, 1972, pp. 589-597. 
9. Roffe, G., "Ground and Flight Testing of Hypersonic Airbreathing Engines," in Hypersonic Airbreathing Propulsion Short Course, NASA Glenn Research Center, Cleveland, OH, April 1999.

10. Davies, W.R. and Bernstein, L., "Heat Transfer and Transition to Turbulence in the Shock-Induced Boundary Layer on a Semi-infinite Flat Plate," Journal of Fluid Mechanics, Vol. 36, 1969, pp. 87-112.

11. Choi, J.Y., Jeung, I.S. and Yoon, Y., "Unsteady Simulation of Model Ram Accelerator in Expansion Tube," AIAA Paper 98-3450, 1998.

12. Yungster, S. and Radhakrishnan, K., "A Fully Implicit Time Accurate Method for Hypersonic Combustion: Application to Shock-Induced Combustion Instability," Shock Waves, Vol. 5, 1996, pp. 293-303.

13. Yungster, S. and Radhakrishnan, K., "Modeling Planar Detonation Wave Propagation Using Detailed Chemistry," AIAA Paper 96-2949, July 1996.

14. Yungster, S. and Radhakrishnan, K., "Computational Study of Reacting Flow Establishment in Expansion Tube Facilities," Shock Waves, Vol. 7, 1997, pp. 335-342.

15. Yungster, S. and Radhakrishnan, K., "Simulation of Unsteady Hypersonic Combustion Around Projectiles," Proceedings, Ninth Annual Symposium, Propulsion Engineering Research Center, Pennsylvania State University, University Park, PA, 1997, pp. 179-183.

16. Yungster, S., Radhakrishnan, K. and Rabinowitz, M.J., "Reacting Flow Establishment in Ram Accelerators: A Numerical Study," J. Prop. and Power, Vol. 14, 1998, pp. 10-17.

17. Yungster, S., "Numerical Study of Shock-Wave Boundary Layer Interactions in Premixed Combustible Gases," AIAA Journal, Vol. 30, No. 10, 1992, pp. 2379-2387.

18. Jachimowski, C.J., "An Analytical Study of the Hydrogen-Air Reaction Mechanism with Application to Scramjet Combustion," NASA TP-2791, Feb. 1988.

19. Radhakrishnan, K. and Hindmarsh, A.C., "Description and Use of LSODE, the Livermore Solver for Ordinary Differential Equations," NASA RP-1327, UCRL-ID-113855, Lawrence Livermore National Laboratory, 1993.

20. Radhakrishnan, K., "Combustion Kinetics and Sensitivity Analysis Computations," in Numerical Approaches to Combustion, E.S. Oran and J.P. Boris, Eds., AIAA, Washington, DC, 1991, pp. 83-128.
21. Radhakrishnan, K., "LSENS-A General Chemical Kinetics and Sensitivity Analysis Code for Homogeneous Gas-Phase Reactions. I. Theory and Numerical Solution Procedures," NASA RP-1328, 1994.

22. Yee, H.C., "Construction of Explicit and Implicit Symmetric TVD Schemes and Their Applications," Journal of Computational Physics, Vol. 68, 1987, pp. 151-179.

23. McBride, B.J. and Gordon, S., "Computer Program for Calculation of Complex Chemical Equilibrium Compositions and Applications. II. Users Manual and Program Description,” NASA RP-1311, 1996.

24. Baldwin, B. and Lomax, H., "Thin Layer Approximation and Algebraic Model for Separated Turbulent Flows," AIAA Paper 78-257.

25. Thibault, P. A., Penrose, J.D., Sulmistras A., Murray, S. B. and Labbe, J.L., "Studies on Detonation Driven Hollow Projectile," in Combustion in High-Speed Flows, J. Buckmaster, T.L. Jackson and A. Kumar, Eds. Kluwer Acad. Pub., Dordrecht, Netherlands, 1994, pp. 421-446.

26. Sasoh, A., Higgins, A.J., Knowlen, C. and Bruckner, A.P., "Hollow Projectile Operation in the Ram Accelerator," Journal of Propulsion and Power, Vol. 12, No. 6, 1996, pp. 1183-1186.

27. Radhakrishnan, K., "LSENS, the NASA Lewis Kinetics and Sensitivity Analysis Code," AIAA Paper 99-2394, June 1999. 
Table 1: Test condition and reactive mixture composition for cases 1-5.

\begin{tabular}{|c|c|c|c|c|c|c|c|c|c|c|}
\hline \multirow{2}{*}{ Case } & \multicolumn{5}{|c|}{ Accelerating Gas $\left(\mathrm{H}_{2}\right)$} & \multicolumn{7}{c|}{ Test Gas } \\
\cline { 2 - 12 } & $\begin{array}{c}p_{10}, \\
\text { bar }\end{array}$ & $\begin{array}{c}T_{10}, \\
\mathrm{~K}\end{array}$ & $\begin{array}{c}p_{20}, \\
\text { bar }\end{array}$ & $\begin{array}{c}T_{20}, \\
\mathrm{~K}\end{array}$ & $M_{20}$ & composition & $\begin{array}{c}p_{5}, \\
\text { bar }\end{array}$ & $\begin{array}{c}T_{5}, \\
\mathrm{~K}\end{array}$ & $M_{5}$ & $M_{\mathrm{CJ}}$ \\
\hline 1 & 0.018 & 288.0 & 0.113 & 579.6 & 1.13 & $2 \mathrm{H}_{2}+\mathrm{O}_{2}+17 \mathrm{~N}_{2}$ & 0.113 & 350.0 & 5.2 & 3.30 \\
\hline 2 & 0.018 & 300.0 & 0.112 & 596.0 & 1.13 & $2 \mathrm{H}_{2}+\mathrm{O}_{2}+17 \mathrm{~N}_{2}$ & 0.112 & 350.0 & 5.2 & 3.30 \\
\hline 3 & 0.018 & 300.0 & 0.112 & 600.3 & 1.13 & $2 \mathrm{H}_{2}+\mathrm{O}_{2}+12 \mathrm{~N}_{2}$ & 0.112 & 350.0 & 5.2 & 3.64 \\
\hline 4 & 0.043 & 300.0 & 0.224 & 543.6 & 1.03 & $2 \mathrm{H}_{2}+\mathrm{O}_{2}+17 \mathrm{~N}_{2}$ & 0.224 & 420.0 & 4.2 & 3.04 \\
\hline 5 & 0.042 & 300.0 & 0.224 & 549.3 & 1.04 & $2 \mathrm{H}_{2}+\mathrm{O}_{2}+12 \mathrm{~N}_{2}$ & 0.224 & 420.0 & 4.2 & 3.34 \\
\hline
\end{tabular}

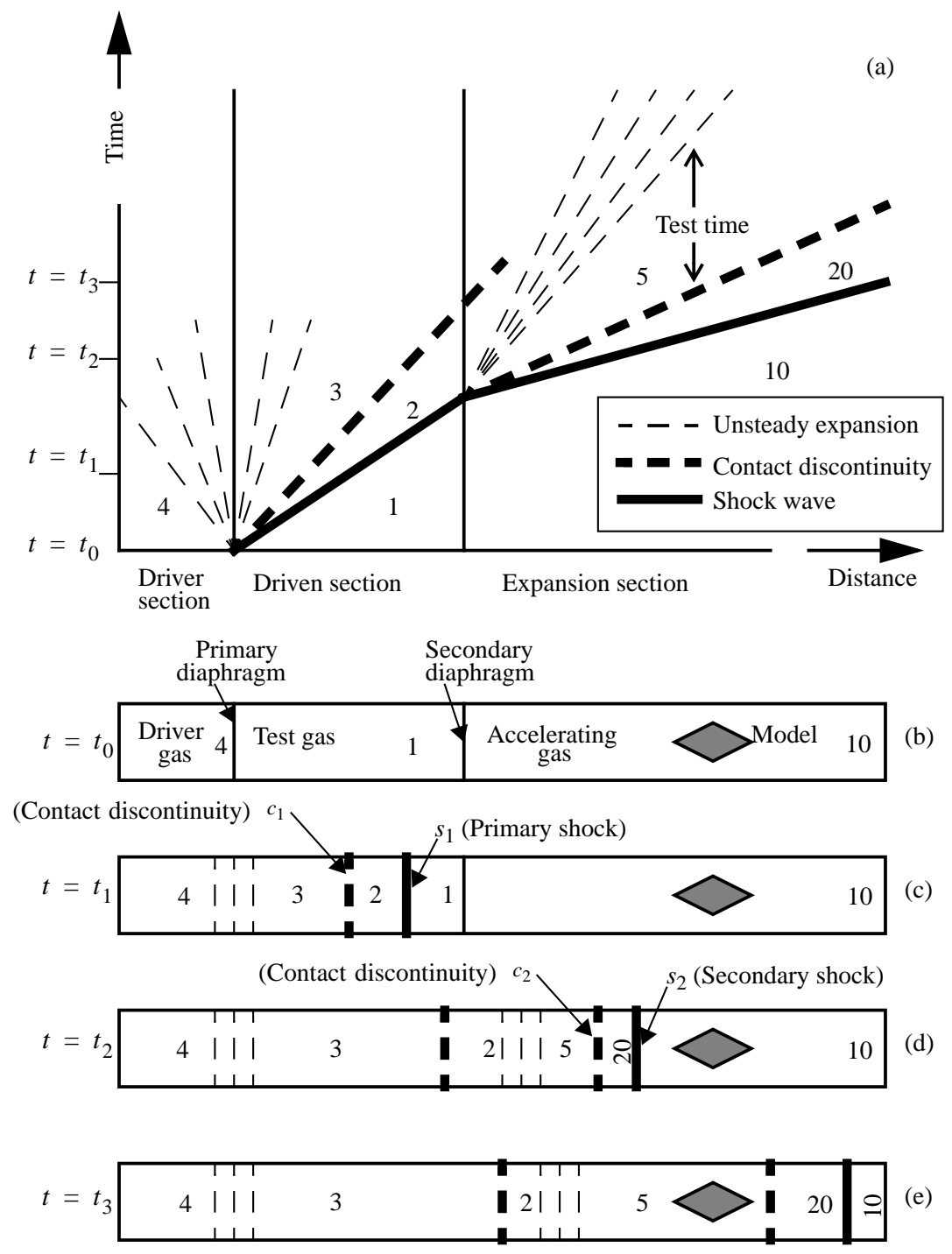

Figure 1. Schematic diagram of expansion tube cycle. Numbers identify flow regions as defined by Trimpi [7]. 


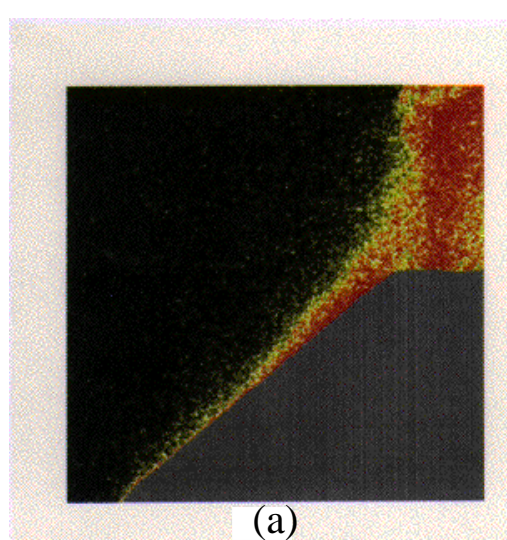

(a)

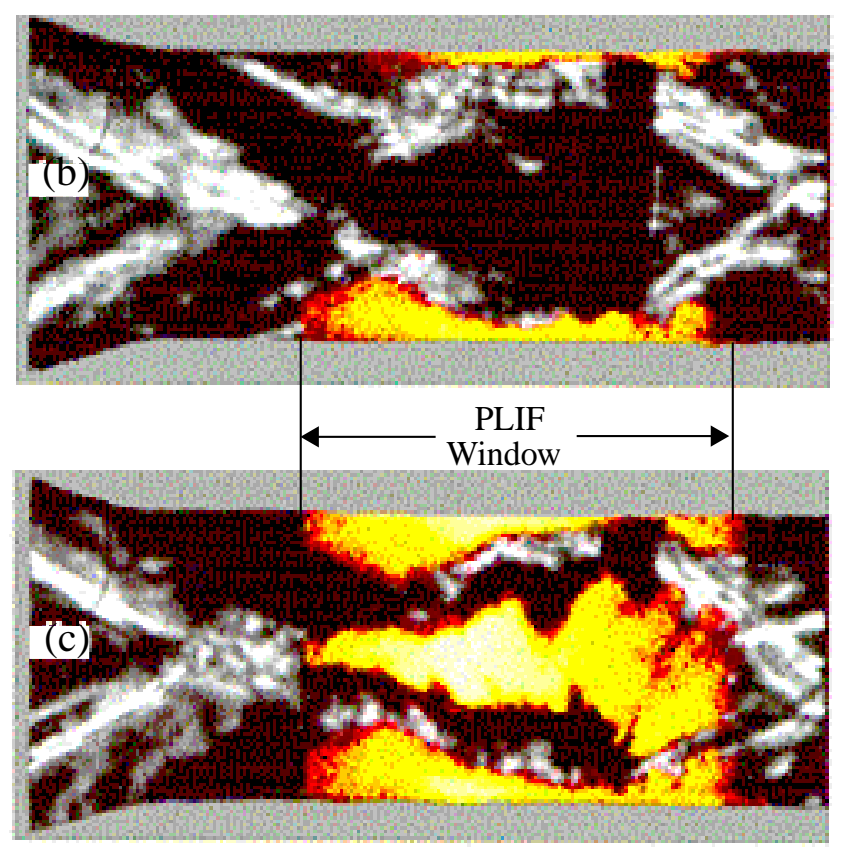

Figure 2. Experimental $\mathrm{OH}$ planar laser induced fluorescence (PLIF) images obtained by Morris et al. [5,6]: (a) case 1 , (b) case 2, and (c) case 3.

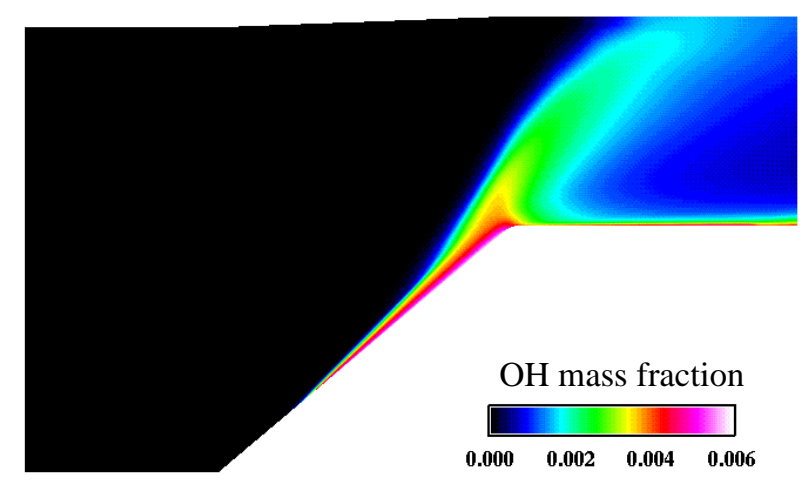

Figure 4. Computed steady state $\mathrm{OH}$ mass fraction contours for case 1 (from Yungster and Radhakrishnan [15]).
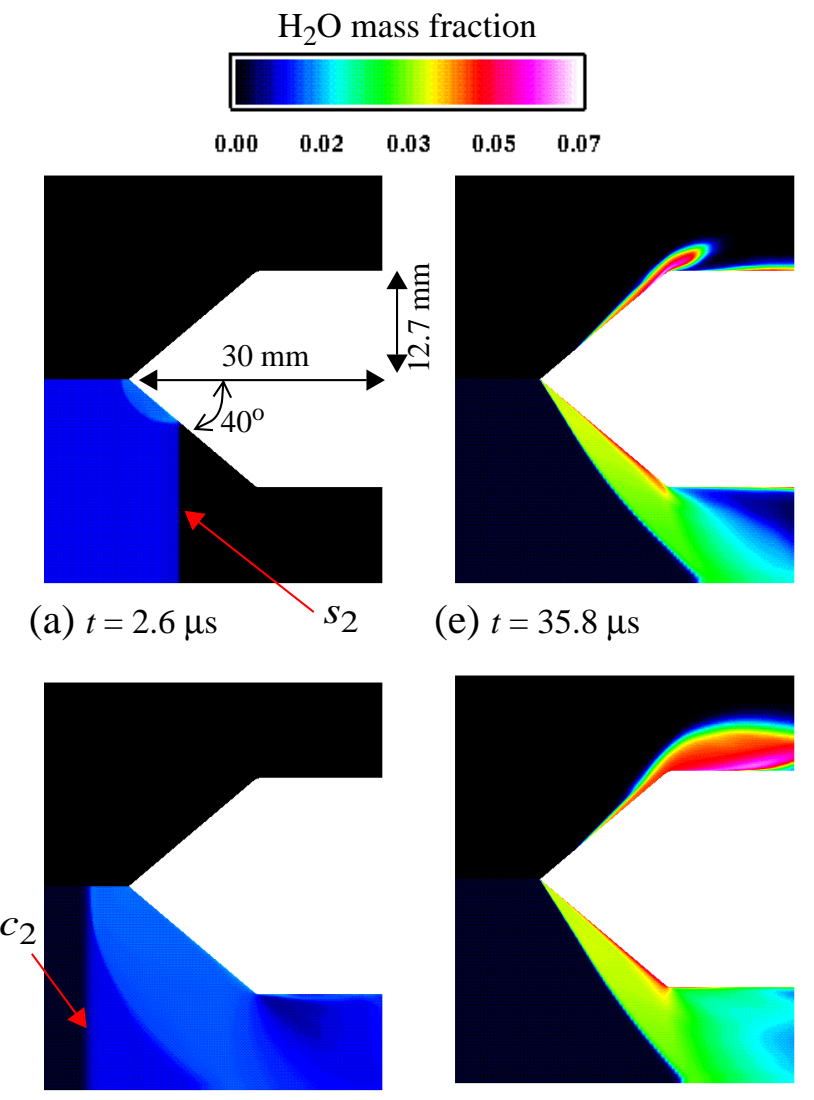

(e) $t=35.8 \mu \mathrm{s}$ (b) $t=11.6 \mu \mathrm{s}$

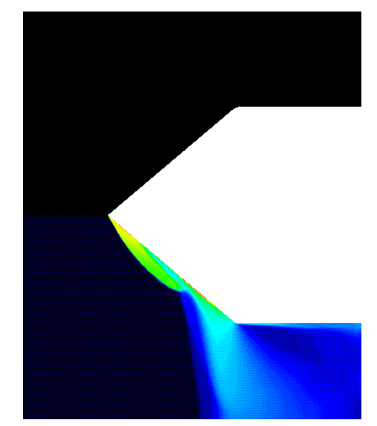

(c) $t=21.2 \mu \mathrm{s}$

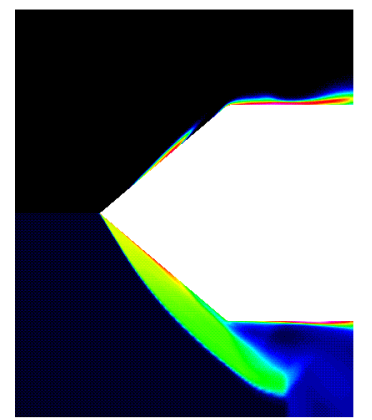

(d)

$t=29.4 \mu \mathrm{s}$

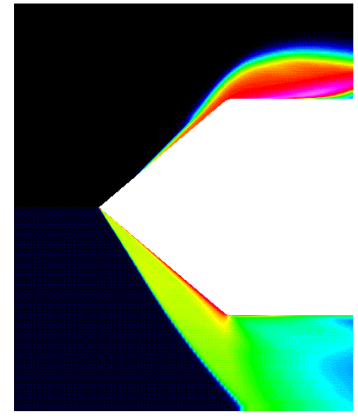

(f) $t=43.8 \mu \mathrm{s}$

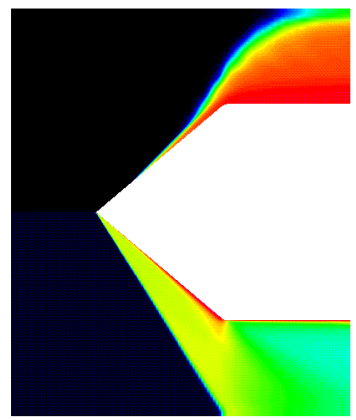

(g) $t=64.6 \mu \mathrm{s}$

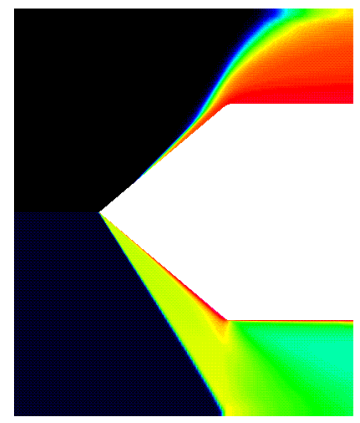

(h)

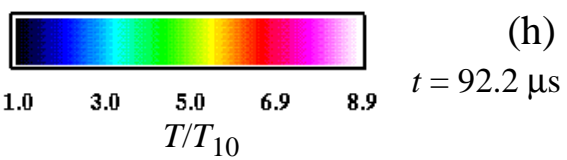

Figure 3. Temporal evolution of expansion tube flowfield for case 1 . The top half of each figure gives water mass fraction contours and the bottom half normalized temperature $\left(T / T_{10}\right)$ contours (from [15]). 


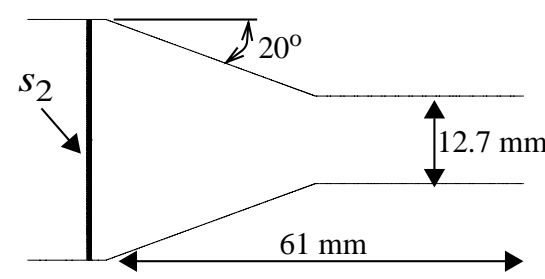

(a) $t=0.0 \mu \mathrm{s} ; T / T_{10}(1.0,3.9,0.04)$

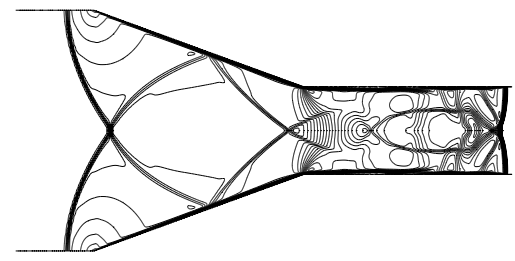

(d) $t=18.42 \mu \mathrm{s}$

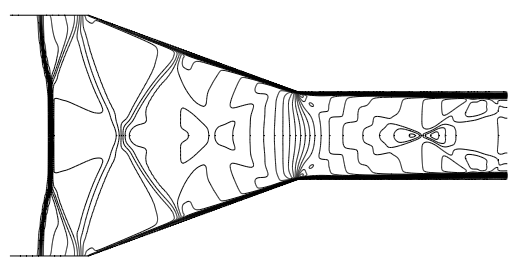

(g) $t=32.49 \mu \mathrm{s}$

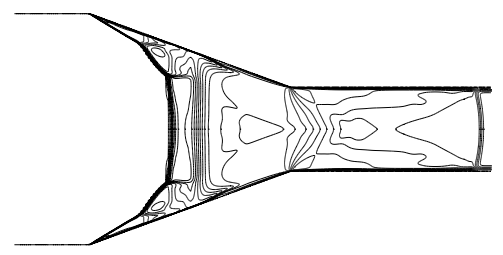

(j) $t=55.80 \mu \mathrm{s}$

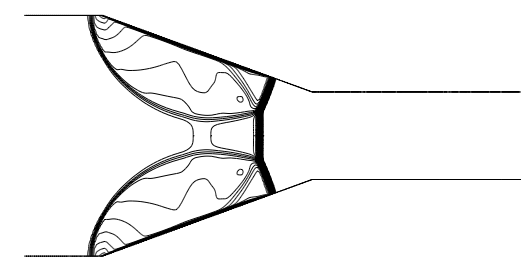

(b) $t=8.28 \mu \mathrm{s}$

(c) $t=11.58 \mu \mathrm{s}$

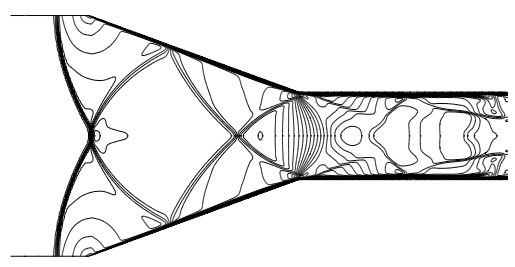

(e) $t=21.89 \mu \mathrm{s}$

(f) $t=26.58 \mu \mathrm{s}$

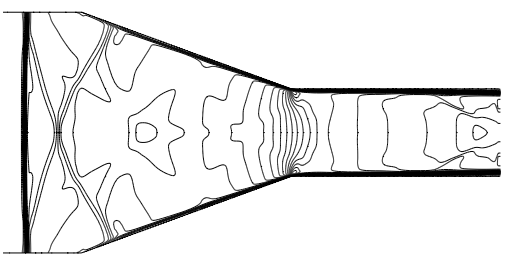

(h) $t=38.16 \mu \mathrm{s}$

(i) $t=43.01 \mu \mathrm{s} ; T / T_{10}(1.0,5.0,0.14)$

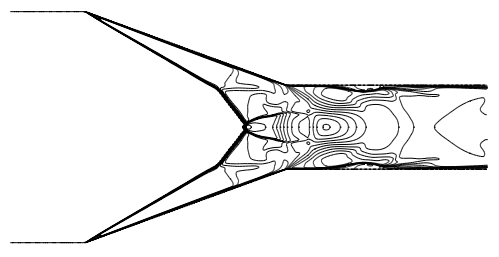

(k) $t=69.61 \mu \mathrm{s} ; T / T_{10}(1.0,5.9,0.18)$
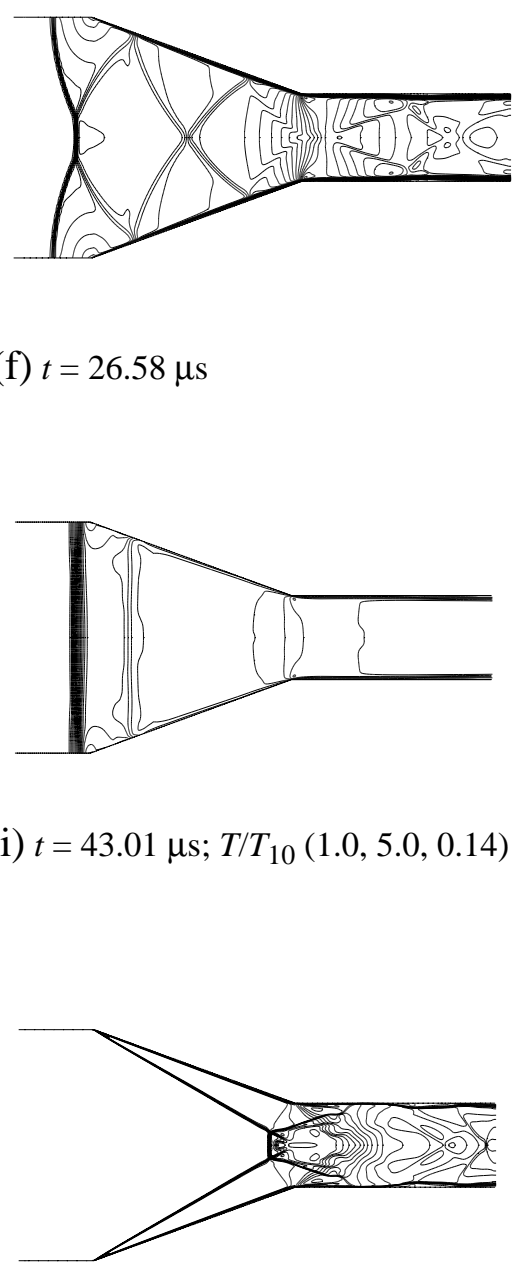

(1) $t=76.18 \mu \mathrm{s}$

Figure 5. Normalized temperature (T/T $\left.T_{10}\right)$ contour lines showing development of initial (i.e., preignition) flowfield for case 2. (In Fig. 5 and subsequent figures (6-9), the contour range, given in the form (minimum, maximum, increment), applies for the plot in which the range is specified and for every subsequent plot, until a new range is defined.) 


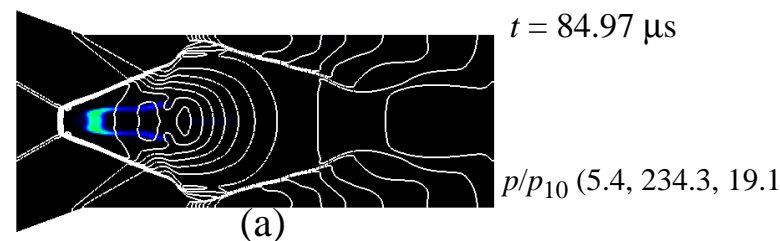

(a)

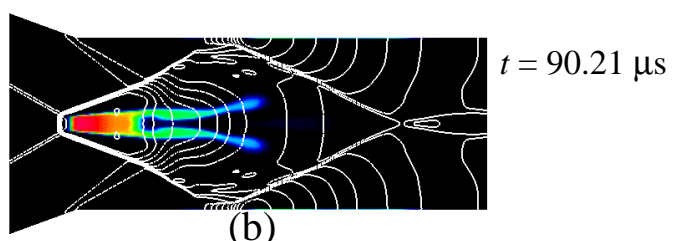

(b)
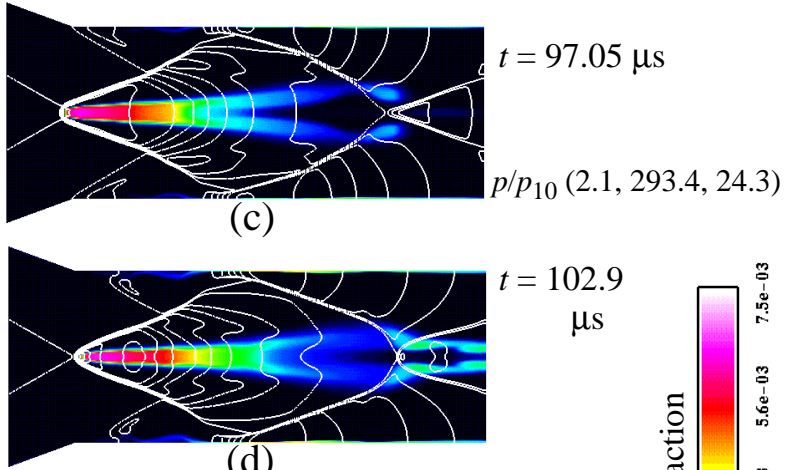

(d)

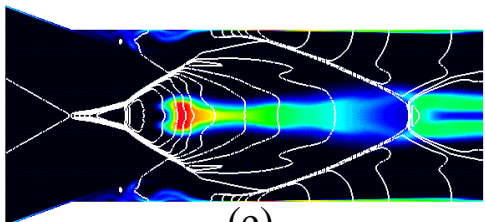

(e)

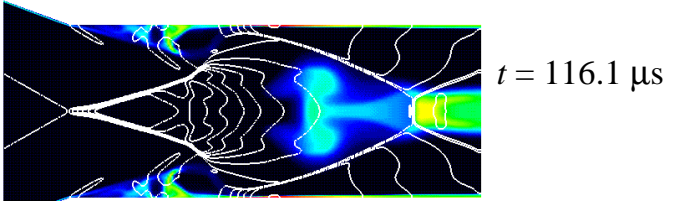

(f)

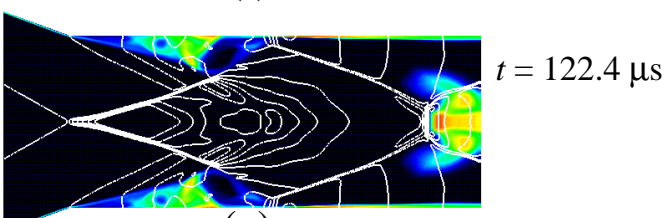

(g)

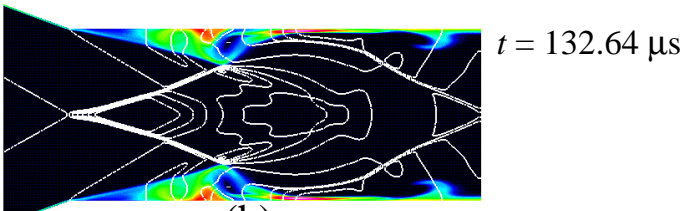

(h)

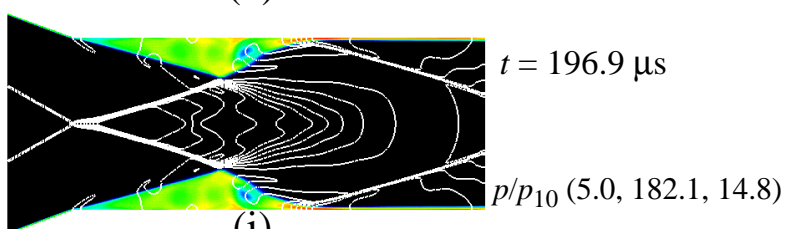

(i)

Figure 6. Temporal evolution of reacting flowfield for case 2, showing overlaid $\mathrm{OH}$ mass fraction contours and normalized pressure $\left(p / p_{10}\right)$ contour lines.

\section{$p / p_{10}(5.5,242.5,21.5)$ \\ $t=87.20 \mu \mathrm{s}$}

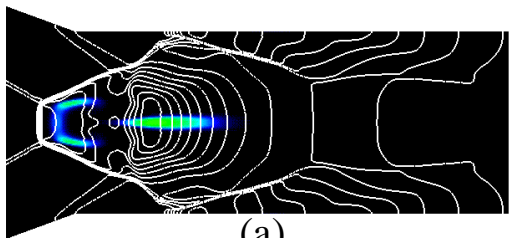

(a)

$t=92.75 \mu \mathrm{s}$

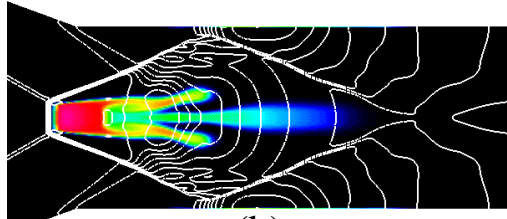

(b)

$p / p_{10}(3.6,283.0,23.3)$

$t=98.96 \mu \mathrm{s}$

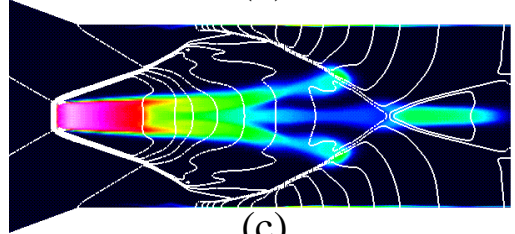

(c)
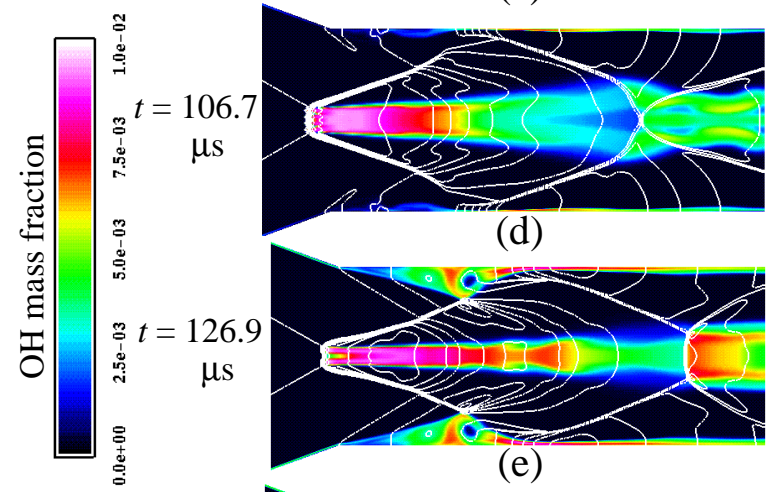

(d)

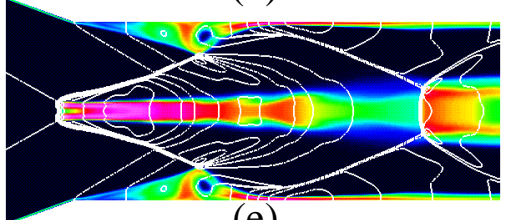

(e)

$$
t=132.4 \mu \mathrm{s}
$$

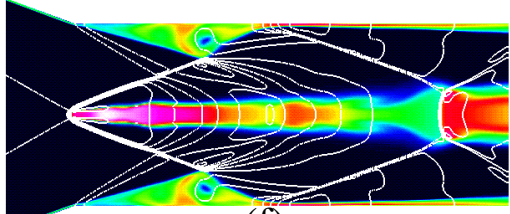

(f)

$t=139.6 \mu \mathrm{s}$

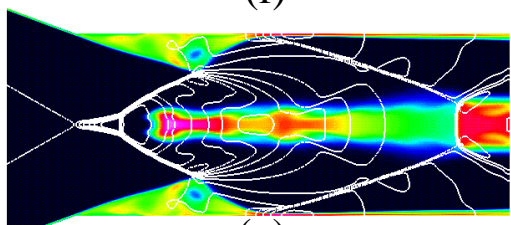

(g)

$t=151.1 \mu \mathrm{s}$

$p / p_{10}(6.2,202.9,16.4)$

$t=194.1 \mu \mathrm{s}$

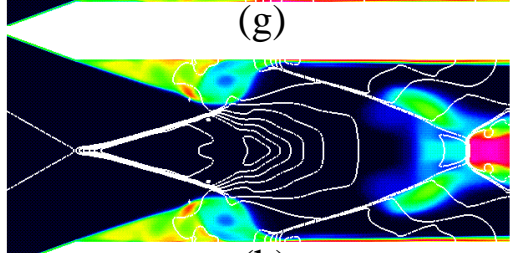

(h)

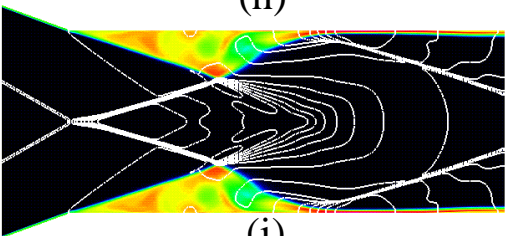

(i)
Figure 7. Temporal evolution of reacting flowfield for case 3, showing overlaid $\mathrm{OH}$ mass fraction contours and normalized pressure $\left(p / p_{10}\right)$ contour lines. 

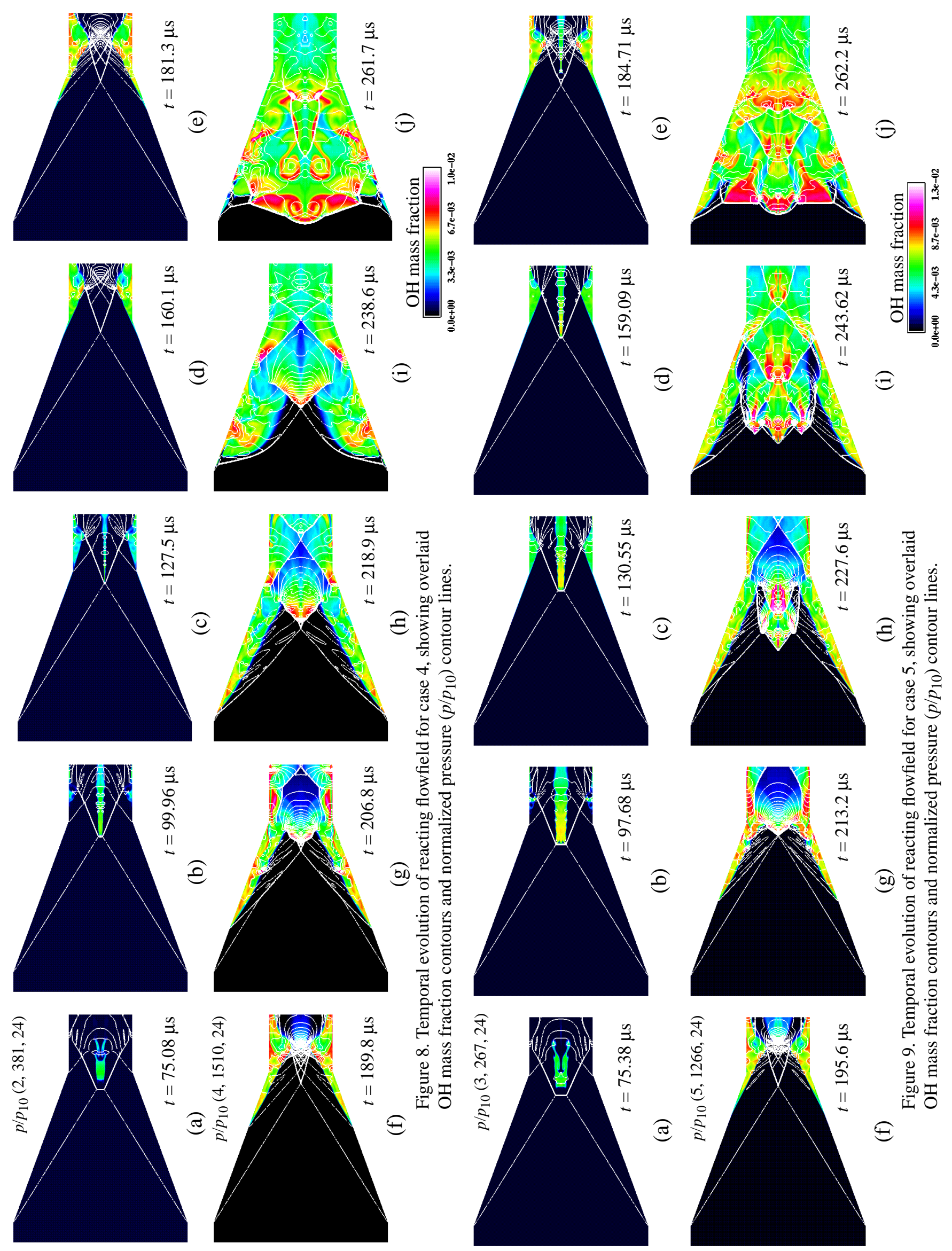


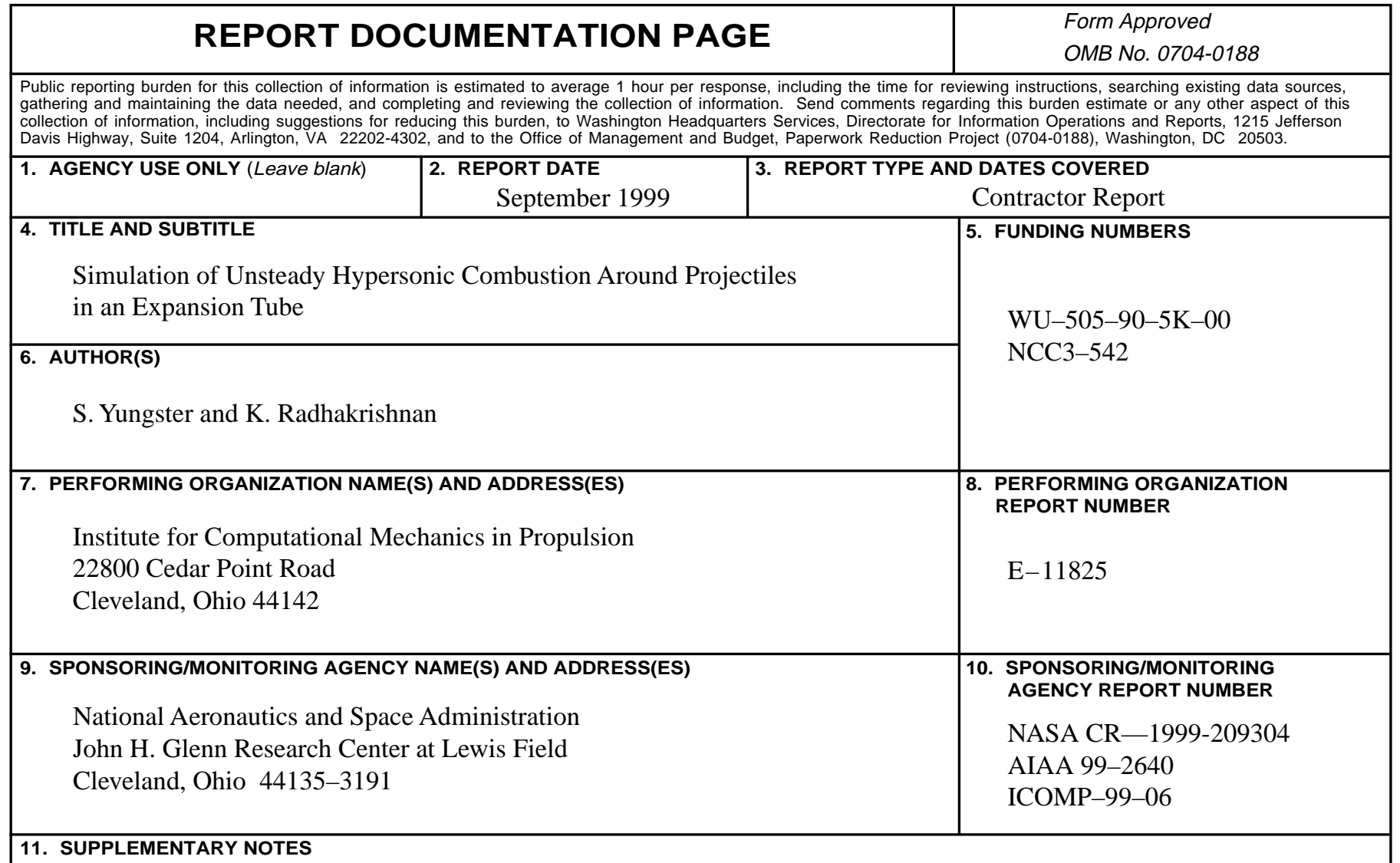

Prepared for the 35th Joint Propulsion Conference and Exhibit cosponsored by AIAA, ASME, SAE, and ASEE, Los Angeles, California, June 20-24, 1999. S. Yungster and K. Radhakrishnan, Institute for Computational Mechanics in Propulsion, NASA Glenn Research Center, Cleveland, Ohio 44135. ICOMP Program Director, Lou Povinelli, organization code 5880, (216) 433-5818.

\begin{tabular}{|l|l|}
\hline 12a. DISTRIBUTION/AVAILABILITY STATEMENT & 12b. DISTRIBUTION CODE
\end{tabular}

Unclassified - Unlimited

Subject Category: $34 \quad$ Distribution: Nonstandard

This publication is available from the NASA Center for AeroSpace Information, (301) 621-0390.

\section{ABSTRACT (Maximum 200 words)}

The temporal evolution of combustion flowfields established by the interaction between wedge-shaped bodies and explosive hydrogen-oxygen-nitrogen mixtures accelerated to hypersonic speeds in an expansion tube is investigated. The analysis is carried out using a fully implicit, time-accurate, computational fluid dynamics code that we developed recently for solving the Navier-Stokes equations for a chemically reacting gas mixture. The numerical results are compared with experimental data from the Stanford University expansion tube for two different gas mixtures at Mach numbers of 4.2 and 5.2. The experimental work showed that flow unstart occurred for the Mach 4.2 cases. These results are reproduced by our numerical simulations and, more significantly, the causes for unstart are explained. For the Mach 5.2 mixtures, the experiments and numerical simulations both produced stable combustion. However, the computations indicate that in one case the experimental data were obtained during the transient phase of the flow; that is, before steady state had been attained.

\section{SUBJECT TERMS}

Oblique detonation wave; Reacting flow; Unsteady combustion; TVD numerical schemes

\begin{tabular}{|c|c|c|}
\hline $\begin{array}{c}\text { 17. SECURITY CLASSIFICATION } \\
\text { OF REPORT } \\
\text { Unclassified }\end{array}$ & $\begin{array}{c}\text { 18. SECURITY CLASSIFICATION } \\
\text { OF THIS PAGE } \\
\text { Unclassified }\end{array}$ & $\begin{array}{c}\text { 19. SECURITY CLASSIFICATION } \\
\text { OF ABSTRACT } \\
\text { Unclassified }\end{array}$ \\
\hline
\end{tabular}

15. NUMBER OF PAGES

18

16. PRICE CODE

A03

20. LIMITATION OF ABSTRACT

Standard Form 298 (Rev. 2-89)

Prescribed by ANSI Std. Z39-18 298-102 